\title{
Structure and superplasticity of the Al-Mg-TM alloy after equal channel angular pressing and rolling
}

\author{
O. Sitdikov ${ }^{\dagger}$ E. Avtokratova, O. Latypova, M. Markushev \\ ${ }^{\dagger}$ sitdikov.oleg@imsp.ru
}

Institute for Metals Superplasticity Problems of RAS, 39 Khalturin str., Ufa, 450001, Russia

\begin{abstract}
The microstructure and superplastic characteristics of the commercial alloy $1570 \mathrm{C}$ (Al-5Mg-0.18Mn-0.2Sc-0.08Zr- $0.01 \mathrm{Fe}-$ $0.01 \mathrm{Si}$, wt.\%) subjected to equal channel angular pressing (ECAP) at the temperature of $325^{\circ} \mathrm{C}$ (about $0.6 \mathrm{~T}_{\mathrm{m}}$ ) to the effective strain of 8 and subsequent isothermal rolling at the same and room temperatures with reductions 86 and $80 \%$, respectively, were compared. It has been found that the development of ultrafine grained structure under ECAP with the grain size of about $1 \mu \mathrm{m}$ and the volume fraction of $0.60-0.70$ led to the unique alloy superplastic properties with the maximum elongations-to-failure up to $3300 \%$ in a wide temperature-strain rate range. Subsequent warm rolling resulted in increased to $0.80-0.85$ volume fraction of ultrafine grains with no changes in their size, while cold rolling, in contrast, provided a heavily deformed (work hardened) structure with a high dislocation density. Despite such difference in the structures formed, the alloy superplastic behavior in both rolled states was nearly similar with maximum elongations about $2800 \%$ at the temperature of $520^{\circ} \mathrm{C}$ and the strain rate of $1.4 \times 10^{-2} \mathrm{~s}^{-1}$. Also, roughly similar microstructures were developed under such optimum alloy superplastic deformation conditions, irrespectively of its rolling temperature.
\end{abstract}

Keywords: aluminum alloy, severe plastic deformation, rolling, superplasticity, microstructure.

\section{Introduction}

Recent investigations have shown that the Al-Mg alloys with the $\mathrm{Mg}$ content more than $4 \mathrm{wt} \%$ and complex additions of transition metals (TM), such as $\mathrm{Mn}, \mathrm{Cr}, \mathrm{Sc}, \mathrm{Zr}$, etc., are advanced structural materials with enhanced service properties [1]. Specifically, these alloys have a high specific strength, an excellent corrosion resistance and a good weldability that make them very promising candidates for a wide use in various kinds of transport systems. At the same time, they are known as quite hard-to-deform materials exhibiting high work hardening and low ductility at ambient temperatures $[1,2]$. However, at elevated temperatures these alloys are able to possess ultra-fine grain (UFG) (grain size $\leq 1 \mu \mathrm{m})$ structures and demonstrate superplastic behavior with very high elongations for aluminum alloys [3]. For instance, such phenomenon was shown in [4-9], where a great potential for enhancement of their superplastic properties was conditioned by producing the UFG structure using severe plastic deformation. One of the most popular and effective methods of severe plastic deformation is equalchannel angular pressing (ECAP), which is commonly used to manufacture UFG plates and rods [4-6, 9-13]. At the same time, regarding wrought $\mathrm{Al}$ alloys, which are much in demand for rolled products [10], development of the costaffordable technology for UFG sheets processing became recently one of the top points for consideration. In this way, method based on combination of ECAP and rolling would be a promising technical procedure with a great commercial potential. However, it should be claimed that nowadays, the data on such processing, especially of aluminium alloys, are quite poor. The present study is dedicated to examine superplastic properties of a commercial Al-Mg-Mn-Sc-Zr alloy $1570 \mathrm{C}$ subjected to ECAP and subsequent rolling.

\section{Experimental procedure}

The commercial aluminum alloy 1570C investigated had the following chemical composition (in wt.\%): Al-5Mg$0.18 \mathrm{Mn}-0.2 \mathrm{Sc}-0.08 \mathrm{Zr}-0.01 \mathrm{Fe}-0.01 \mathrm{Si}$. Conventionally cast and homogenized ingots were machined into plates of $150 \times 150 \times 30 \mathrm{~mm}$ and subjected to ECAP at a temperature of $325^{\circ} \mathrm{C}$ to a total effective strain of $e=8$ by route $\mathrm{Bcz}$ (rotation by $90^{\circ}$ around the normal axis to the plate plane between passes) using a die with rectangular cross-section and channel inner and outer angles of $90^{\circ}$ and $0^{\circ}$, respectively. The ECAP temperature of $325^{\circ} \mathrm{C}$ (about $0.6 T_{\mathrm{m}}$ ) was chosen since it was well documented in the previous works [12-16] that this temperature is the most suitable for $\mathrm{Al}-\mathrm{Mg}-\mathrm{Sc}(-\mathrm{Zr})$ alloys with the Mg content of about 5-6\% to form UFG structures with large fractions of high angle boundaries.

The warm rolling was carried out under constant temperature $325^{\circ} \mathrm{C}$ of a sample and rolls (i.e. under isothermal conditions) with the total reduction of $86 \%$, and the cold rolling was performed at ambient temperature with the total reduction of $80 \%$. In both cases the rolling direction of the samples with sizes of $70 \times 25 \times 12 \mathrm{~mm}$ was coincided with the last pressing direction in ECAP.

The alloy microstructures evolved were examined in the sample longitudinal and/or plate/rolling planes using conventional methods of optical metallography, scanning and transmission electron microscopy. Metallographic 
observations were carried out using a Nikon L-150 optical microscope after etching of the samples with a standard Keller's reagent. Specimens for scanning and transmission electron microscopy examinations were electropolished at $20 \mathrm{~V}$ in a $30 \% \mathrm{HNO}_{3}$ and $70 \% \mathrm{CH}_{3} \mathrm{OH}$ solution at a temperature of $-28^{\circ} \mathrm{C}$ in a Tenupol- 5 twin-jet polishing unit. Scanning electron microscopy with electron backscatter diffraction (EBSD) was performed employing a field emission microscope TESCAN MIRA $3 \mathrm{LMH}$ equipped with the Oxford Instruments HKL Channel 5 system. Transmission electron microscopy was implemented using an electron microscope JEOL-2000EX.

The sizes and volume fractions of (sub)grains were measured in optical microscopy (transmission electron microscopy) using the line-intercept and point-count methods, respectively. The angular parameters of the structure, including the average misorientation angle of the intercrystallite boundaries $\Theta_{\text {ave }}$ and fraction of high-angle boundaries $f_{\mathrm{HABs}}$, were derived from EBSD analysis. The scan area was varied from $100 \times 100 \mu \mathrm{m}^{2}$ to $200 \times 200 \mu \mathrm{m}^{2}$ and the scanning step size was $0.1-0.2 \mu \mathrm{m}$, depending on the dispersion and homogeneity of the analyzed structure. The standard noise reduction procedure was implemented to clean up the non-indexed points [17]. In EBSD maps, the low-angle $\left(2^{\circ}<\Theta<15^{\circ}\right)$ and high-angle $\left(\Theta \geq 15^{\circ}\right)$ boundaries were indicated using white and black lines, respectively.
Therewith, the intergranular boundaries with misorientation angles less than $2^{\circ}$ were not considered.

Tensile tests were carried out on the universal testing machine Instron 1185 in the temperature range of $350-520^{\circ} \mathrm{C}$ under constant crosshead speed conditions using specimens with a gauge part $3 \times 6 \times 1.5 \mathrm{~mm}^{3}$ machined along the pressing or rolling direction.

\section{Results and discussion}

The initial cast and homogenized alloy had an equiaxed grain structure with an average grain size of about $25 \mu \mathrm{m}$ (Fig. 1a,b) and predominantly high angle intercrystallite boundaries (Fig. 1d). It was also characterized by near uniformly distributed and coherent with the aluminum matrix $\mathrm{Al}_{3}(\mathrm{Sc}, \mathrm{Zr})$ dispersoids of $5-10 \mathrm{~nm}$ in diameter with the number density of about $1 \times 10^{4} \mu^{-3}$ (Fig. 1c).

Under ECAP, the structure of the alloy transformed into relatively uniform bimodal one with the size and volume fraction of ultrafine grains of about $1 \mu \mathrm{m}$ and $0.60-0.70$, respectively (Fig. 2). Consequently, near one third of this structure was represented by slightly elongated fragments of remnant original grains having the mean size of about $20 \times 12 \times 18 \mu \mathrm{m}$ (Fig. 2a,b). Such a structure developed could be conditioned by continuous dynamic recrystallization $[12,13,15-18]$.

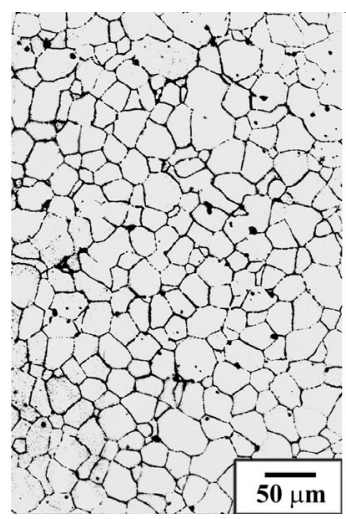

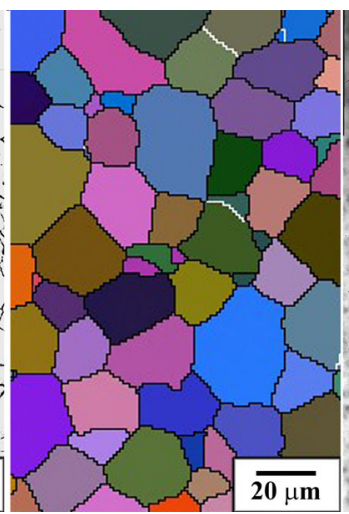

b

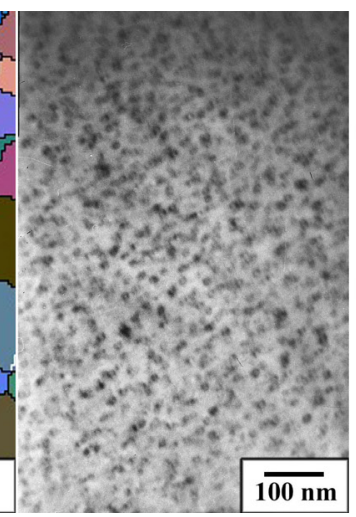

c

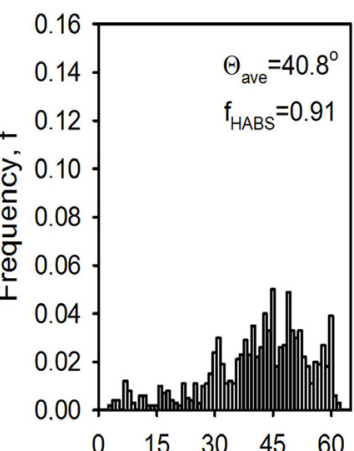

Misorientation angle,

d

Fig. 1. Structure $(\mathrm{a}-\mathrm{c})$ and misorientations distribution of the intercrystallite boundaries (d) in the initial state of the alloy 1570C: optical microscopy (a); EBSD analysis (b, d) and transmission electron microscopy (c).

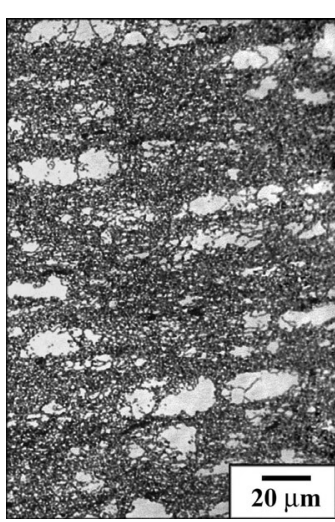

a

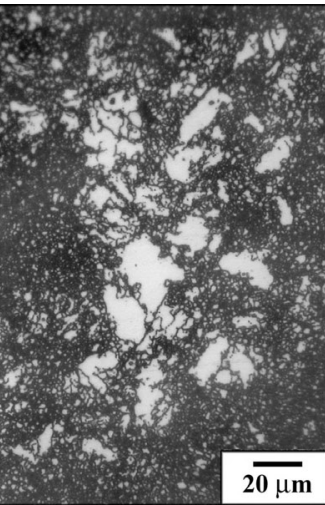

b

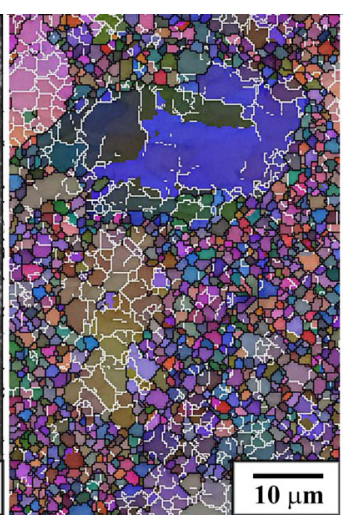

c

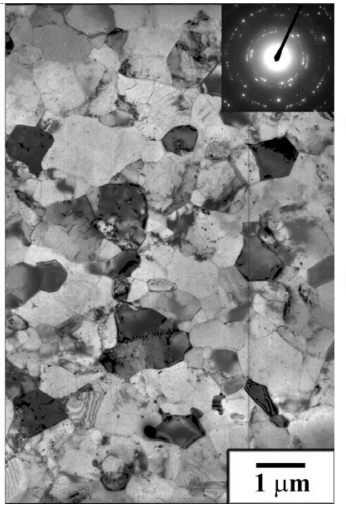

d

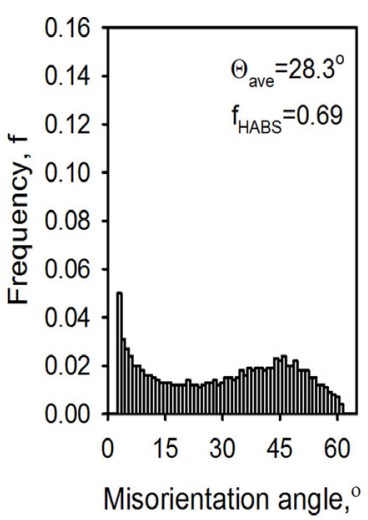

e

Fig. 2. Structure $(\mathrm{a}-\mathrm{d})$ and misorientation distribution of the intercrystallite boundaries (e) in the alloy 1570C after ECAP: longitudinal section (a); plate section (b-e); optical microscopy $(a, b)$; EBSD analysis (c,e); transmission electron microscopy (d): hereinafter, the selected area electron diffraction patterns were obtained from areas with diameters of $10 \mu \mathrm{m}$. Pressing direction is horizontal. 
Warm rolling after ECAP resulted mainly in increased homogeneity of the UFG structure owing to continuation of recrystallization processes (Fig. 3). Therewith, the volume fraction of new ultrafine grains increased to $0.80-0.85$, suggesting that additional grain refinement took place mainly through subdivision of remnant grains. At the same time, the other parameters of structure processed, e.g. the size and shape of ultrafine (sub)grains, as well as the angular parameters that were developed during ECAP remained virtually unchanged. This may suggest that the plastic deformation in the UFG regions occurred mainly by grain boundary sliding, which was attributed to the comparatively high rolling temperature [18].

Comparison of Figs. 2 and 3 also clearly shows that the shape of coarse grains became more pancaked upon rolling in accordance to the macroscopic straining of a billet. Thus at large reductions, the opposite grain boundaries could frequently come in touch with each other, thereby leaving more equiaxed and finer grains. Such mechanism of grain refinement may be considered as geometric dynamic recrystallization [18].

Cold rolling, in contrast, resulted in pancaking of both ultrafine and remnant grains, followed by formation of a workhardened lamellar-like microstructure with slightly prevailing deformation-induced low-angle boundaries (Fig. 4).
However, the mean misorientation angle of boundaries was still of quite high value. Ttransmission electron microscopy analysis reveals high-density of dislocations arranged in almost equiaxed cellular substructures with the average crystallite size of $0.2-0.5 \mu \mathrm{m}$. It is also worth to note that the deformation microstructure developed during cold rolling was apparently homogeneous on the mesoscopic level, as after warm rolling. It is safe to assume that in both cases this homogeneity may be mainly attributed to a uniform distribution of the $\mathrm{Al}_{3}(\mathrm{Sc}, \mathrm{Zr})$ dispersed precipitates in the alloy matrix (Fig. 1c) [19]. The latter are known to effectively interact with the lattice dislocations during deformation preventing their rearrangement on the long distances and thereby promoting homogenization of dislocation slip even at high strains $[12,19]$.

It was found, that after ECAP the alloy possessed extraordinary high strain rate superplastic behavior at $475^{\circ} \mathrm{C}$ with maximum elongations, $\delta$, up to $3300 \%$ at the initial strain rate of $\dot{\varepsilon}=5.6 \times 10^{-2} \mathrm{~s}^{-1}$ (Fig. 5a). Besides, $\delta$, exceeding $2000 \%$ and corresponding strain rate sensitivity coefficient, $m>0.35$ (Fig. 5b) were measured in a wide strain rate range from $1.4 \times 10^{-2}$ to $1.4 \times 10^{-1} \mathrm{~s}^{-1}$. Moreover, the alloy exhibited the low temperature superplastic behavior: at $350^{\circ} \mathrm{C}$ and $\dot{\varepsilon}=1.4 \times 10^{-2} \mathrm{~s}^{-1}$, it demonstrated $\delta$ more than $1000 \%$. Meanwhile, it should be claimed, that the superplastic

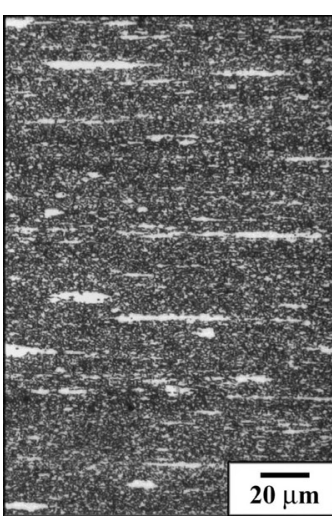

a

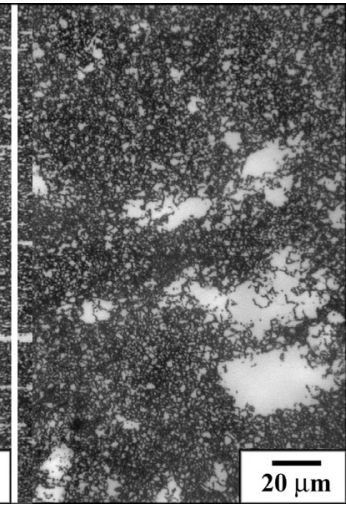

b

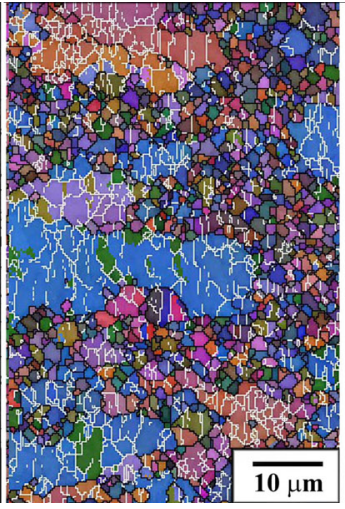

c

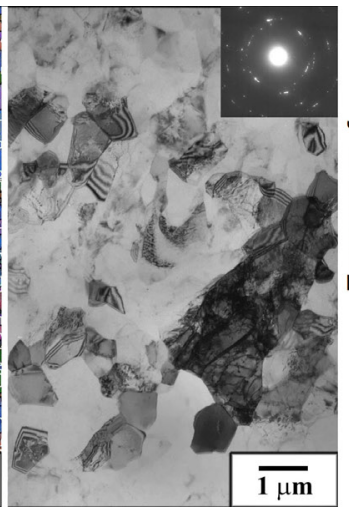

d

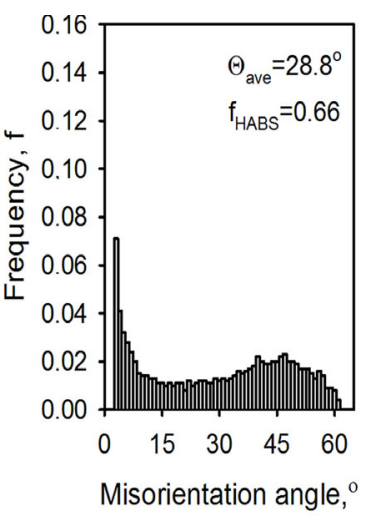

e

Fig. 3. Structure $(\mathrm{a}-\mathrm{d})$ and misorientation distribution of the intercrystallite boundaries (e) in the alloy 1570C after ECAP and warm rolling: longitudinal section (a); rolling plane (b-e); optical microscopy (a,b); EBSD analysis (c, e); transmission electron microscopy (d). Rolling direction is horizontal.

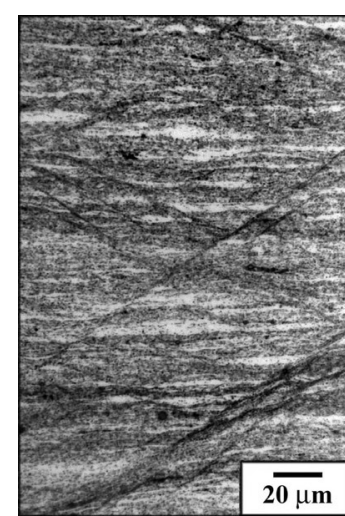

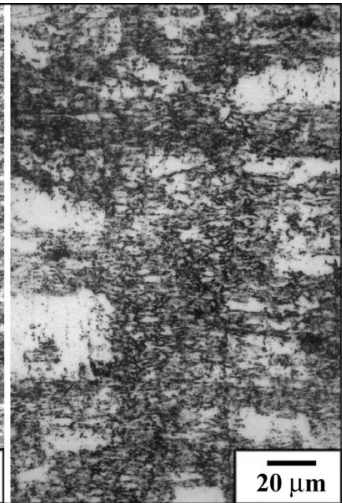

b

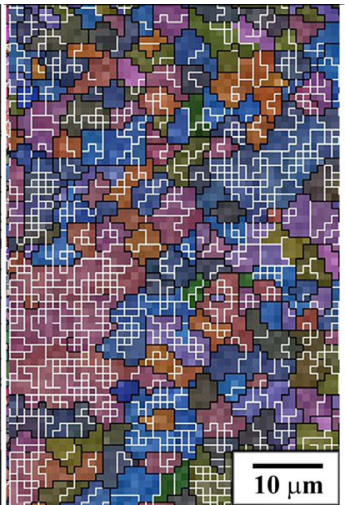

C

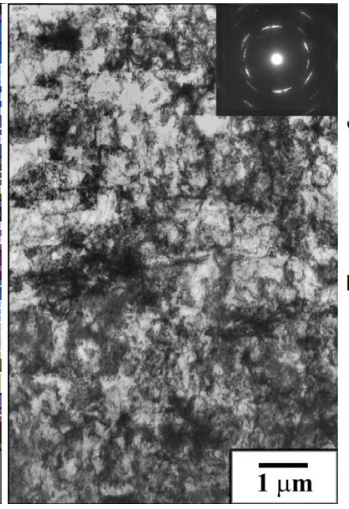

d

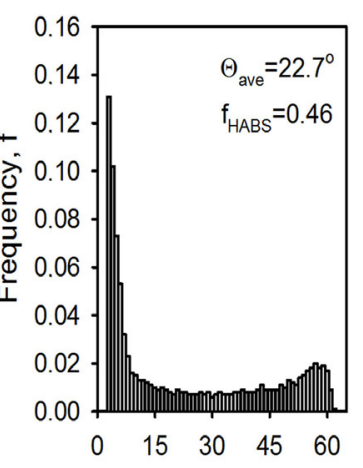

Misorientation angle, ${ }^{0}$

e

Fig. 4. Structure $(\mathrm{a}-\mathrm{d})$ and misorientation distribution of the intercrystallite boundaries (e) in the alloy 1570C after ECAP and cold rolling: longitudinal section (a); rolling plane (b-e); optical microscopy (a,b); EBSD analysis (c, e); transmission electron microscopy (d). Rolling direction is horizontal. 
characteristics have been preserved extremely high in both rolled alloy states, even though the optimum of superplasticity was shifted to higher temperatures and lower strain rates. Besides, it was surprisingly to find out the roughly similar alloy superplastic behavior after warm and cold rolling in spite of the significant difference in the microstructures developed before tension (Figs. 3 and 4). Thus, the alloy in both states exhibited high strain rate superplasticity with the maximum $\delta$ of about $2800 \%$ at $520^{\circ} \mathrm{C}$ and $\dot{\varepsilon}=1.4 \times 10^{-2} \mathrm{~s}^{-1}$.

Microstructures of tensile samples developed in the alloy after ECAP during static and dynamic annealing under optimum superplastic conditions are represented in Fig. 6.
They manifest that one of the main reasons for the superior alloy superplastic behavior is a high thermal stability of the UFG structure processed via ECAP. In fact, the alloy static annealing, taking place in the sample grip part, for about 0.3 hour at a temperature of $475^{\circ} \mathrm{C}$ resulted in a normal grain growth from about 1 to $2.4 \mu \mathrm{m}$ only. Simultaneously, tension led to a more significant dynamic grain growth to 9.8 and $6.6 \mu \mathrm{m}$ in the tensile and transverse directions, respectively, with the grain aspect ratio of 1.48 after elongation to $3300 \%$. However, such value was in a good agreement with the typical one obtained at conventional superplasticity, where a high contribution of grain boundary sliding to the total elongation

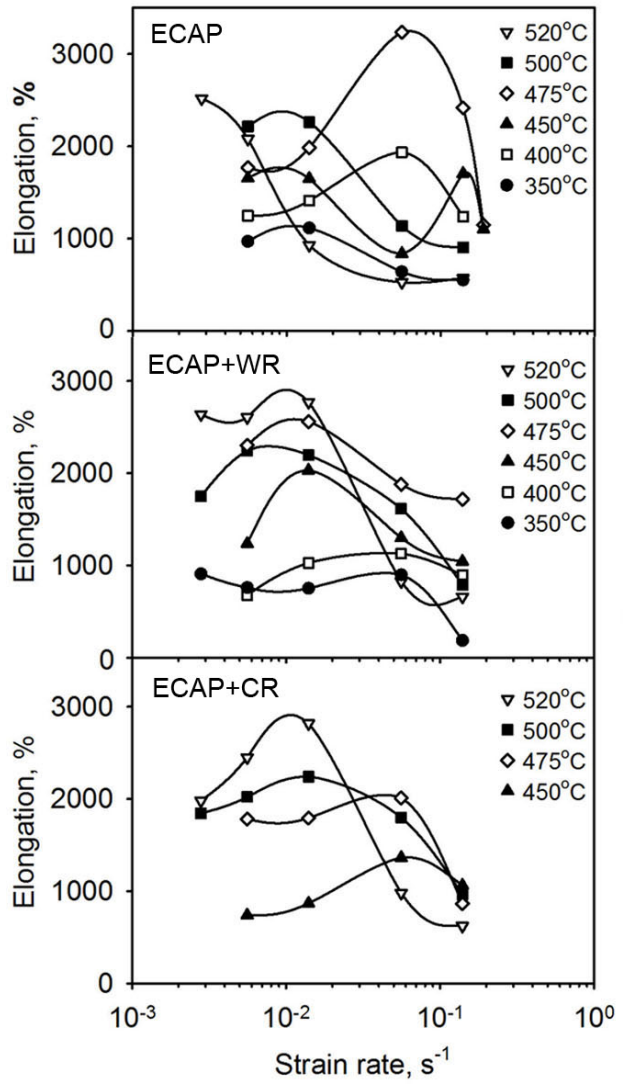

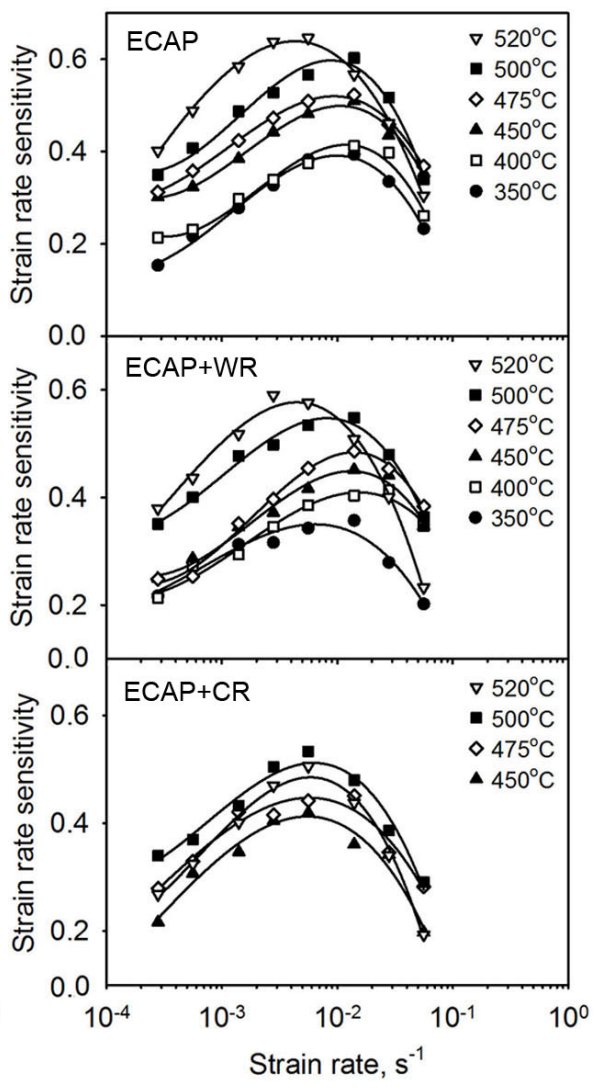

b

Fig. 5. Temperature-strain rate dependencies of elongations-to-failure (a) and strain rate sensitivity coefficient (b) obtained for the alloy $1570 \mathrm{C}$ in various processing states: WR (warm rolling); CR (cold rolling).

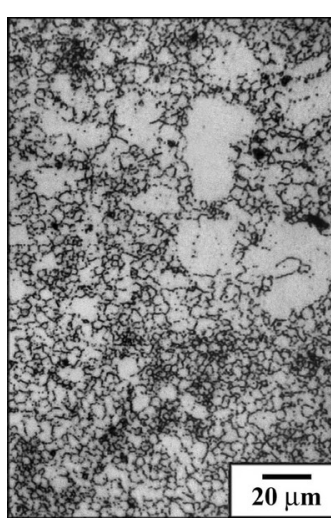

a

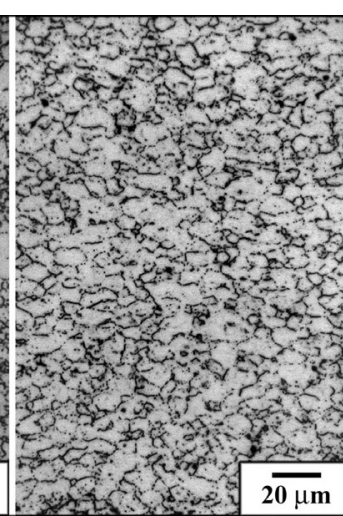

b

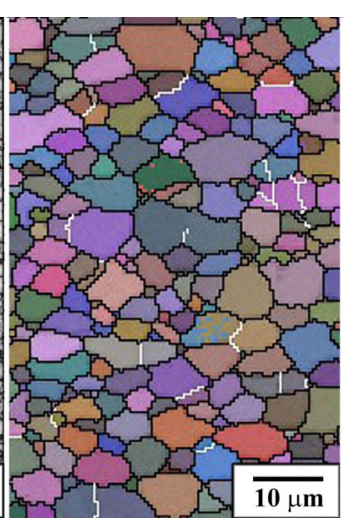

c

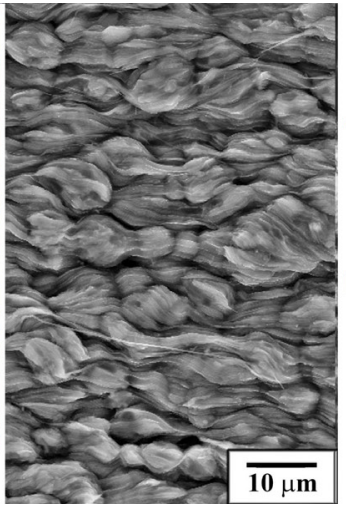

d

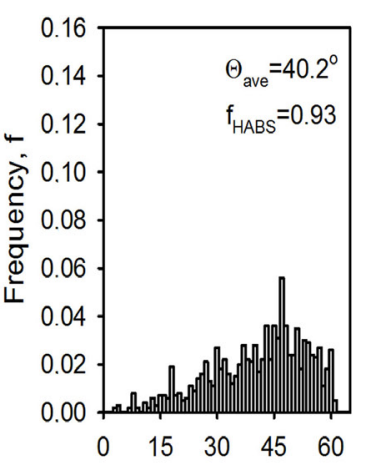

Misorientation angle,

e

Fig. 6. Structure (a-c); deformation relief $(\mathrm{d})$ and misorientation distribution of intercrystallite boundaries (e) after tension at $520^{\circ} \mathrm{C}$ and $1.4 \times 10^{-2} \mathrm{~s}^{-1}$ of the alloy $1570 \mathrm{C}$ subjected to ECAP: grip part, plate plane (a); gauge part, plate plane (b-e); optical microscopy (a,b); EBSD analysis (c,e); scanning electron microscopy $(\mathrm{d})$. 
takes place [6]. This result was also supported by the analysis of deformation relief, where signs of grain boundary sliding were clearly evident (Fig 6d). Thus, the present study proves that complex additions of $\mathrm{Mn}, \mathrm{Zr}$ and $\mathrm{Sc}$ to the aluminum alloys are quite effective to stabilize their UFG structure, ensuring extensive operation of the grain boundary sliding. The effect is most likely due to high thermal stability of precipitates of $\mathrm{Al}_{6} \mathrm{Mn}$ and especially $\mathrm{Al}_{3}(\mathrm{Sc}, \mathrm{Zr})$ phases, reported, for example, in $[5,15,19]$. A strong pinning effect of such dispersoids restricts a drastic grain growth at elevated temperatures and prevents degradation of superplastic properties. This allows a sustained alloy behavior promoting extremely high elongations-to-failure.

Typical microstructures developed under optimum superplastic conditions (i.e. at $T=520^{\circ} \mathrm{C}$ and $\dot{\varepsilon}=1.4 \times 10^{-2} \mathrm{~s}^{-1}$ ) in the alloy after ECAP and subsequent warm and cold rolling are shown in Figs. 7 and 8, respectively. Rather uniform fine-grained structures were found in the grip parts of tensile samples in both cases (Figs. $7 \mathrm{a}$ and $8 \mathrm{a}$ ). Therewith the average grain size in fine-grained regions was about $6.1 \mu \mathrm{m}$ in the material after warm rolling and $5.6 \mu \mathrm{m}-$ after cold rolling. Besides, some relatively coarse grains with a size of $20-60 \mu \mathrm{m}$ were present in these structures. Moreover, there were no significant differences in the microstructures evolved under dynamic annealing conditions, as shown in Figs. $7 \mathrm{~b}-\mathrm{e}$ and $8 \mathrm{~b}-\mathrm{e}$. The sizes of the grains developed in the gauge parts were as high as 13.5 and $9.3 \mu \mathrm{m}$ after warm rolling and 13.4 and $9.9 \mu \mathrm{m}$ after cold rolling along and across of tensile axis, respectively. Also, both grain structures evolved were characterized by similar boundary misorientation distributions and mean values of structure angular parameters after superplastic deformation. It seems that almost uniform fine-grained structures in the alloy, subjected to ECAP and subsequent warm rolling, mainly developed due to normal static/dynamic grain growth occurring during superplastic flow [18]. In contrast, the formation of the new grain structure in the cold rolled alloy can occur during annealing by continuous static recrystallization $[18,20]$, when a great number of straininduced grains in the heavily deformed matrix transform to potential nuclei for static recrystallization. The latter can grow under further straining and consume neighboring grains containing higher dislocation densities. Thus, the different structural mechanisms may be responsible for finegrain structure formation during superplsticity of the alloy subjected to ECAP and rolling at different temperatures. Nevertheless, it was interesting to find out the near similar microstructures developed during static and dynamic annealing at $520^{\circ} \mathrm{C}$, providing close and extremely high superplastic ductilities (Fig. 5).

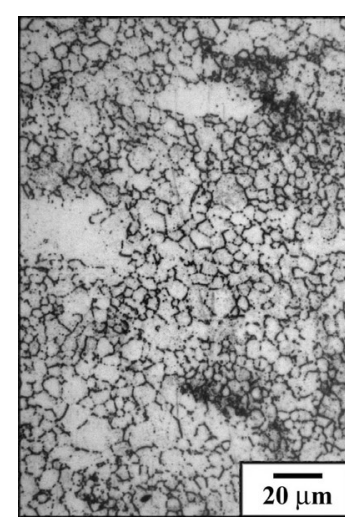

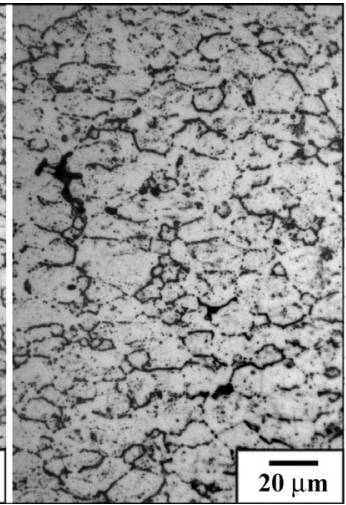

b

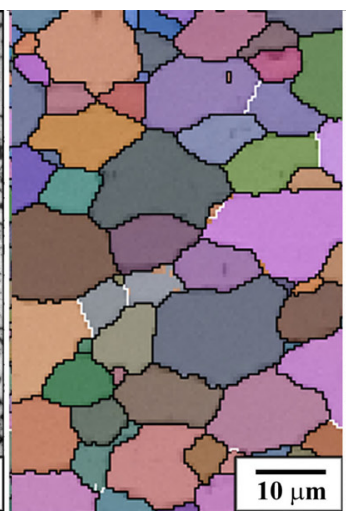

c

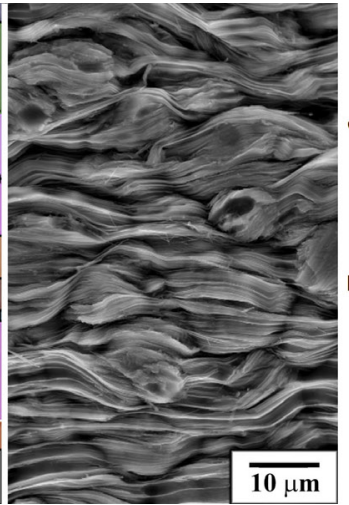

d

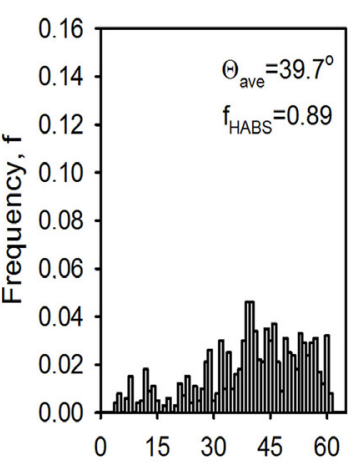

Misorientation angle, ${ }^{0}$

e

Fig. 7. Structure (a-c); deformation relief (d) and misorientation distribution of intercrystallite boundaries (e) after tension at $520^{\circ} \mathrm{C}$ and $1.4 \times 10^{-2} \mathrm{~s}^{-1}$ of the alloy $1570 \mathrm{C}$ subjected to ECAP and subsequent warm rolling: grip part, rolling plane (a); gauge part, rolling plane (b-e); optical microscopy (a,b); EBSD analysis (c,e); scanning electron microscopy $(\mathrm{d})$.

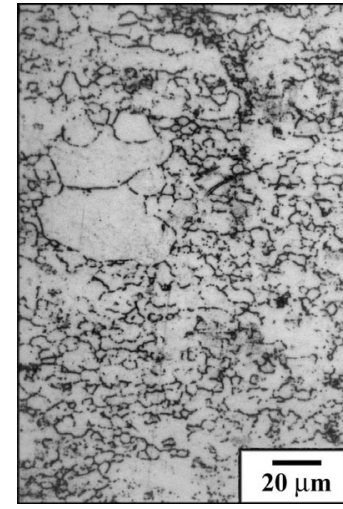

a

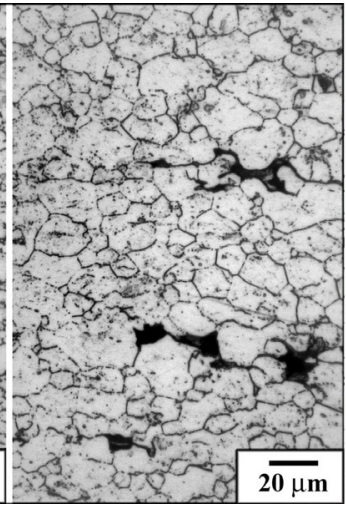

b

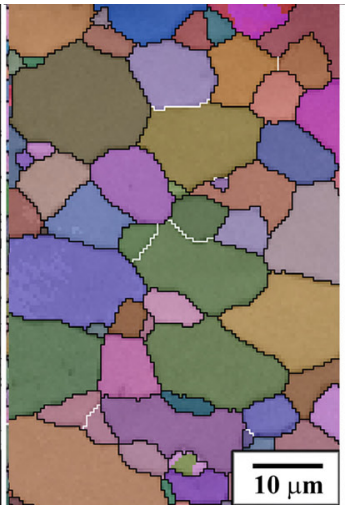

c

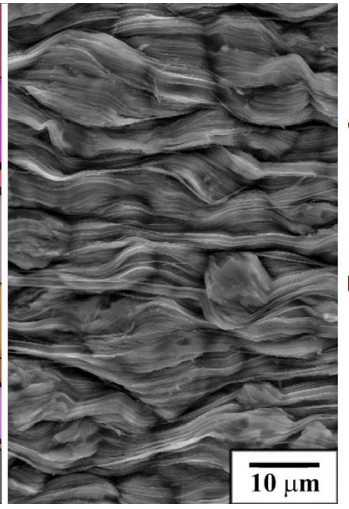

d

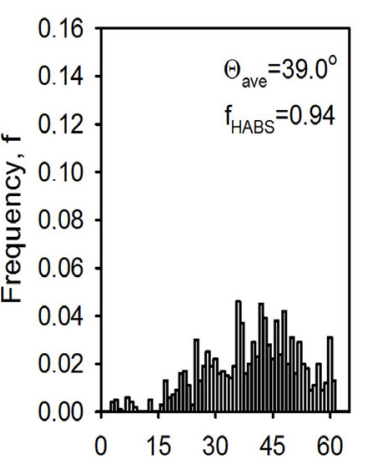

Misorientation angle, ${ }^{\circ}$

e

Fig. 8. Structure (a-c); deformation relief (d) and misorientation distribution of intercrystallite boundaries (e) after tension at $520^{\circ} \mathrm{C}$ and $1.4 \times 10^{-2} \mathrm{~s}^{-1}$ of the alloy $1570 \mathrm{C}$ subjected to ECAP and subsequent cold rolling: grip part, rolling plane (a); gauge part, rolling plane (b - e); optical microscopy (a,b); EBSD analysis (c, e); scanning electron microscopy (d). 


\section{Summary}

Microstructure and superplastic properties of the Al-5Mg$0.18 \mathrm{Mn}-0.2 \mathrm{Sc}-0.08 \mathrm{Zr}-0.01 \mathrm{Fe}-0.01 \mathrm{Si}$ alloy were investigated upon combination of ECAP at $325^{\circ} \mathrm{C}$ and subsequent isothermal rolling at various temperatures to high strains. The main results may be summarized as follows.

1. ECAP to total strain 8 resulted in the bimodal structure composed by ultrafine grains with the grain size of about $1 \mu \mathrm{m}$ and the volume fraction of about $0.60-0.70$ and remnant fragments of original grains. After ECAP the alloy demonstrated extraordinary high strain rate superplastic behavior at $475^{\circ} \mathrm{C}$ in a strain rate range from $1.4 \times 10^{-2}$ to $1.4 \times 10^{-1} \mathrm{~s}^{-1}$ with $\delta$ exceeding $2000 \%$, as well as low-temperature superplastic behavior at $350^{\circ} \mathrm{C}$ and $\dot{\varepsilon}=1.4 \times 10^{-2} \mathrm{~s}^{-1}$ with $\delta \geq 1000 \%$.

2. The optimum superplastic behavior with maximum ductility of $3300 \%$ was observed at tension of the alloy subjected to ECAP at a temperature of $475^{\circ} \mathrm{C}$ with initial strain rate $5.6 \times 10^{-2} \mathrm{~s}^{-1}$. The extremely high alloy elongations were mainly attributed to the enhanced thermal stability of the UFG structure due to presence of coherent $\mathrm{Al}_{3}(\mathrm{Sc}, \mathrm{Zr})$ precipitates with high number densities.

3. Cold rolling of the alloy after ECAP resulted in replacement of the processed structure with prevailed amount of ultra-fine grains by a heavily deformed cellular one with the cell size of $0.2-0.5 \mu \mathrm{m}$. In contrast, warm rolling carried out at the temperature of previous ECAP led mainly to increasing the volume fraction of UFG grains to $0.80-0.85$, while the other structural characteristics after ECAP remained virtually unchanged.

4. The alloy superplastic properties were preserved extremely high after both warm and cold post-ECAP rolling. In both states the alloy exhibited high strain rate superplasticity in a wide temperature-strain rate interval with the maximum $\delta \approx 2800 \%$ at $520^{\circ} \mathrm{C}$ and $\dot{\varepsilon}=1.4 \times 10^{-2} \mathrm{~s}^{-1}$. Such superplastic behavior was conditioned by development of roughly similar microstructures under both the static and dynamic annealing conditions irrespective of the alloy initial structural state.

5. The present study demonstrates the feasibility of manufacturing the sheets from the Al-Mg-TM alloys with excellent superplastic characteristics via extensive grain refinement by combination of ECAP and conventional rolling.

\section{References}

1. Y. A. Filatov, V.I. Yelagin, V. V.Zacharov. Mater. Sci. Eng. A. 280, 97 (2000). DOI: 10.1016/S0921-5093(99)00673-5

2. T.G. Nieh, L.M. Hsiung, J. Wadsworth,
R. Kaibyshev. Acta Mater. 46, 2789

(1998). DOI: 10.1016/S1359-6454(97)00452-7

3. X. Wang, Q. Li, R. Wu, X. Zhang, L. Ma. Adv. Mater. Sci. Eng. 2018, 17 (2018). DOI: 10.1155/2018/7606140

4. Z. Horita, M. Furukawa, M. Nemoto, A.J. Barnes, T.G. Langdon. Acta Mater. 48, 3633 (2000). DOI: 10.1016/S1359-6454(00)00182-8

5. S. Lee, A. Utsunomiya, H. Akamatsu, K. Neishi, M. Furukawa, Z. Horita, T. G. Langdon. Acta Mater. 50, 553 (2002). DOI: 10.1016/S1359-6454(01)00368-8

6. F.Musin, R.Kaibyshev, Y.Motohashi, G. Itoh. Scripta Mater. 50, 511 (2004). DOI: 10.1016/j.scriptamat.2003.10.021

7. V.N. Perevezentsev, M.Y. Shcherban, M.Y. Murashkin, R.Z. Valiev. Tech. Phys. Letters. 33, 648 (2007). DOI: $10.1134 /$ S106378500708007X

8. K. Turba, P. Málek, M. Cieslar. Mater. Sci. Eng. A. 462, 91 (2007). DOI: 10.1016/j.msea.2006.01.178

9. E. Avtokratova, O. Sitdikov, M. Markushev, R. Mulyukov. Mater. Sci.Eng. A. 538, 386 (2012). DOI: 10.1016/j.msea.2012.01.041

10. H. Akamatsu, T. Fujinami, Z. Horita, T.G. Langdon. Scripta Mater. 44, 759 (2001). DOI: 10.1016/S1359-6462(00)00666-7

11. M. V. Markushev. Letters on Materials. 1(1), 36 (2011). (in Russian) DOI: 10.22226/2410-3535-2011-1-36-42

12. O.Sh. Sitdikov, E.V. Avtokratova, R.I. Babicheva. Phys. Met. Metall. 110, 153 (2010). DOI: $10.1134 / \mathrm{S} 0031918 \mathrm{X} 10080053$

13. O. Sitdikov, E. Avtokratova, T. Sakai, K. Tsuzaki. Met. Mater. Trans. A. 44. 1087 (2013). DOI: 10.1007/ s11661-012-1438-4

14. Patent RF № 0002575264 C1, 20.02.2016. (in Russian)

15. E. Avtokratova, O. Sitdikov, O. Mukhametdinova, M. Markushev, S. V. S. N. Murty, M. J. N. V. Prasad, B.P. Kashyap. J. Alloy and Compd. 673, 182 (2016). DOI: 10.1016/j.jallcom.2016.02.207

16. O. Sitdikov, T. Sakai, E. Avtokratova, R. Kaibyshev, K. Tsuzaki, Y. Watanabe. Acta Mater. 56, 821 (2008). DOI: 10.1016/j.actamat.2007.10.029

17. Channel 5: User Manual. Oxford Instruments HKL (2007). https://caf.ua.edu/wp-content/uploads/docs/JEOL7000F-Oxford_Channel_5_User_Manual.pdf

18. F.J. Humphreys, M. Hatherly. Recrystallization and related annealing phenomena. Oxford, Elsevier (2004) $658 \mathrm{p}$.

19. Y.W. Riddle, T.H. Sanders. Met. Mater. Trans. 35A, 341 (2004). https://link.springer.com/content/pdf/ 10.1007\%2Fs11661-004-0135-3.pdf

20. A. Belyakov, T. Sakai, H. Miura, R. Kaibyshev, K. Tsuzaki. Acta Mater. 50, 1547 (2002). DOI: 10.1016/S1359-6454(02)00013-7 